\title{
MUSEUS EM UNIVERSIDADES PÚBLICAS: ENTRE O CAMPO CIENTÍFICO, O ENSINO,A PESQUISA E A EXTENSÃO
}

\author{
Emanuela Sousa Ribeiro' \\ Universidade Federal de Pernambuco
}

\section{RESUMO:}

Este artigo tem como foco a análise da gestão dos museus e acervos universitários, relacionando-a com as funções da universidades: o ensino, a pesquisa e a extensão. Utiliza-se, como ferramenta de análise, a teoria dos campos de Pierre Bourdieu, a fim de discutir como opera o campo científico nas universidades públicas e quais ganhos, simbólicos e materiais, os museus universitários propiciam, ou não. O campo científico e os museus e acervos universitários são analisados em cada uma das três funções das universidades - ensino, pesquisa e extensão - e conclui-se que a extensão universitária possui potencial para apoiar os museus universitários, oferecendo o apoio institucional que $o$ ensino e a pesquisa já não podem oferecer no atual contexto acadêmico nacional.

\section{PALAVRAS-CHAVE:}

Museu Universitário. Patrimônio Universitário. Campo Científico. Gestão de Museus.

\begin{abstract}
:
This article focuses on the analysis of the university's museums and collections management, making a relation between that and the universities' functions: teaching, research and extension. As an analysis tool, it's used the field theory of Pierre Bourdieu, to discuss how to operate the scientific field in public universities and to know which gains, symbolic and material, university museums provide, or not. The scientific field and university museums and collections are analyzed in each of the three functions of universities - teaching, research and extension - and it's concluded that the university extension has the potential to support university museums, offering the institutional support that teaching and research can no longer provide the current national academic context.
\end{abstract}

\section{KEY-WORDS:}

University Museum. University Heritage. Scientific Field. Museums Management.

I Professora do Departamento de Antropologia e Museologia da UFPE e do Curso de Mestrado Profissional em Gestão Pública da UFPE. E-mail: emanuela.ribeiro@ufpe.br 


\section{Museus universitários: discutindo conceitos}

Este artigo analisa a gestão dos museus e acervos universitários, situados na interface entre a gestão das instituições de ensino superior públicas, o campo científico/acadêmico e a já complexa tarefa da gestão de museus. Assim, trabaIhamos com a intersecção entre as análises da área da teoria social, da gestão pública e da museologia.

No âmbito da gestão pública é importante perceber que, quando tratamos dos museus e acervos das instituições de ensino superior públicas, estamos tratando de instituições cuja gestão está vinculada ao funcionamento, regras e impedimentos da administração da coisa pública, com as vicissitudes do bom ou mau funcionamento do Estado brasileiro.

Ao mesmo tempo, tratando-se de museus universitários, não se pode desconhecer que estes estão inseridos nas lógicas e práticas do campo científico (BOURDIEU, 2004), sendo influenciados pelas práticas de pesquisadores, professores e administradores deste campo, tal como está configurada a vida acadêmica no Brasil desde a estruturação do atual sistema de ensino superior universitário, após a Reforma Universitária de 1968.

E, por fim, nunca é demais ressaltar a complexidade das práticas relacionadas à gestão dos museus, cujas necessidades de conservar, investigar, comunicar, interpretar e expor, para fins de preservação, estudo, pesquisa, educação, contemplação e turismo (BRASIL, 2009), demandam, cada vez mais, articulação entre eficiência técnica e o atendimento às demandas da sociedade contemporânea.Assim, acreditamos ser importante discutir o funcionamento dos museus universitários, refletindo sobre as particularidades deste tipo de gestão, que está inserido em um campo com regras de funcionamento bastante particulares.

O universo empírico de onde partem nossas análises surgiu a partir das visitas de campo realizadas durante o projeto Valorização do patrimônio científico e tecnológico brasileiro ${ }^{2}$, do qual somos parceiros institucionais em Pernambuco. O projeto está voltado para a identificação e valorização do patrimônio cultural de ciência e tecnologia, que compõe a enorme maioria - mas não a totalidade dos acervos dos museus universitários, e os trabalhos de campo desenvolvidos ao longo do projeto nos propiciaram contatos com o cotidiano de diversos pequenos museus das universidades de Pernambuco, tanto públicas quanto privadas.

Por outro lado, a Universidade Federal de Pernambuco, instituição pública de ensino superior onde desenvolvemos nossa atividade profissional é uma das nossas principais fontes de observação cotidianas, comparação com outras instituições e, principalmente, nossa principal fonte de inquietações e de instigação para a colocação deste problema de pesquisa.

Assim, apesar do recorte empírico regional, acreditamos que os impasses e problemas identificados ao longo do trabalho se reproduzem na grande maioria das universidades do país.

Antes de qualquer coisa, é relevante retomar, ainda que brevemente, a discussão sobre a natureza dos museus e acervos universitários, perguntando-nos qual a peculiaridade deste tipo de museu, cuja diversidade temática é tão ampla.

Efetivamente, há museus universitários de todas as áreas do conhecimento, que poderiam estar agrupados em torno de seus similares não universitários. Por exemplo, o banco de dados do comitê internacional do ICOM para museus

2 Projeto de pesquisa coordenado pelo Prof. Dr. Marcus Granato, que visa "ampliar o conhecimento sobre conjuntos de objetos de C\&T existentes no país, propiciando sua melhor preservação e um estudo teórico sobre o patrimônio de C\&T no Brasil". Disponível em: <http://www.mast.br/projetovalorizacao/ new-page-2.html>.Acesso em: 22 jul. 2013. 
e coleções universitárias (UMAC - International Comittee for University Museums and Collections ${ }^{3}$ ) listas 757 (museus universitários de história cultural e arte), I 33 (museus universitários de etnologia e antropologia), 3 I 3 (museus universitários de história e arqueologia), 3 I 8 (museus universitários de medicina), 1057 (museus de história natural e ciências naturais), entre outros.

Certamente os museus de etnologia e antropologia, por exemplo, poderiam estar vinculados apenas ao comitê internacional do ICOM destinado aos museus de etnografia (ICME - International Comittee for Museums and Collections of Ethnography), assim como cada um dos demais museus, poderia estar vinculado apenas ao comitê especializado de sua área, de acordo com temática das suas coleções.

Porém, acreditamos que, na maior parte das vezes, o fato de ser um museu universitário é determinante para sua configuração institucional, tanto no nível da sua missão e objetivos, quanto no nível de suas políticas de gestão institucional. No dizer de Gil (2005, p. 46) “os museus universitários, como tais, têm características específicas que fazem com que atravessem transversalmente a tipologia museológica"

Acreditamos que isso se dá em virtude da origem da coleção, bem como em virtude do seu uso após a musealização. Do ponto de vista da origem, trata-se de levar em consideração a motivação para a construção das coleções e, claro, o contexto no qual se inseremos acervos. Podemos ilustrar essa afirmativa com a declaração dos ministros da União Européia sobre o patrimônio universitário:

O 'patrimônio universitário' engloba todos os bens tangíveis e intangíveis relacionados com as instituições de ensino superior e o seu corpo institucional, bem como com a comunidade acadêmica composta por professores/pesquisadores e estudantes, e todo o meio ambiente social e cultural que dá forma a este patrimônio.

O 'patrimônio universitário' é composto por todos os traços, tangíveis e intangíveis, da atividade humana relacionada ao ensino superior.

É uma grande fonte de riqueza acumulada, que nos remete diretamente à comunidade acadêmica de professores/pesquisadores e estudantes, seus modos de vida, valores, conquistas e sua função social, assim como os modos de transmissão do conhecimento e capacidade para a inovação (UNIÃO EUROPÉIA, 2005).

Percebe-se que a conceituação do patrimônio universitário, que designa - acervo dos museus universitários, identifica a origem das coleções com a "comunidade acadêmica, seus modos de vida, valores e função social" - mesmo quando a conceituação foi produzida a partir de um fórum político, de não especialistas. Assim, retomando o exemplo das coleções de etnografia, podemos afirmar que uma coleção etnográfica construída no âmbito universitário tem, potencialmente, características distintas de outras coleções, construídas fora das universidades. Mudam os sistemas de classificação das peças, muda a documentação associada, muda o uso, muda o público-alvo etc.

O sistema de valores, modos de vida e função social das universidades e, consequentemente do seu patrimônio e dos seus museus é, portanto, um dos principais elementos que constituem o acervo dos museus universitários. Esta parte do acervo, conquanto seja em geral constituído por um patrimônio

3 Banco de dados completo disponível em: <http://publicus.culture.hu-berlin.de/collections/>. Acesso em: 22 jul. 2013. 
imaterial e de difícil apreensão, ajuda a explicar o porquê da existência de características e de questões que são próprias deste tipo de museu, independente da tipologia das suas coleções materiais.

Trata-se de um conjunto de valores, saberes, modos de vida, que falam de uma cultura universitária, surgida já no século XIII, em plena Idade Média, intimamente associada com a pretensão de universalidade dos saberes e com a experiência da autonomia universitária (VERGER, 2002, p. 579-580).

Estas características da universidade medieval - a autonomia e a universalidade, pretensas, pelo menos -mantêm-se até os dias atuais e somam-se à experiência científica do século XVIII, que propugna o controle da natureza e o desenvolvimento técnico-científico como inevitavelmente positivo (BAZZO, 20 I I, p. 93-94). Trata-se de uma cultura universitária, que também é parte dos museus universitários, independente da sua especialidade.

A perspectiva da existência de uma cultura universitária pressupõe, portanto, a necessidade de difundi-la, torná-la acessível aos não universitários, de maneira a trabalhar também na consolidação da Universidade como locus portador de determinadas características, específicas e privilegiadas, da sociedade contemporânea.

Assim como os demais museus - e não poderia ser diferente -, os museus universitários existem também para legitimar valores e experiências da sociedade em que estão inseridos, conforma afirma Poulot:

$\mathrm{Na}$ escala das coletividades, os mecanismos de aquisição, de transmissão e de conservação das obras [...], envolvem um horizonte de expectativa ligado às representações de um grupo social, a uma sensibilidade local, às experiências, próximas ou longínquas, sociais e culturais, dos quais ele participa (POULOT, 2003, p. 40).

Entre as muitas representações levadas a efeito pelos diversos tipos de museus, há que considerar também o seu papel na representação do saber universitário, de caráter acadêmico, diferenciado daquele saber que circula fora dos seus muros. Tal saber configura-se em um "microcosmo dotado de suas leis próprias” (BOURDIEU, 2004, p. 20), cuja legitimação depende, intrinsecamente, da sua capacidade de funcionar autonomamente, como campo científico, conforme analisaremos no item seguinte.

Diante do exposto acreditamos que podemos fazer uma síntese das particularidades dos museus universitários a partir das delimitações propostas por Gil (2005, p. 49):

Deve estar integrado numa universidade [...];

Deve ter a preocupação de estudar, conservar e apresentar convenientemente as coleções que possui, usando-as em ações científico-pedagógicas[...];

Tem como uma das suas missões constituir a "face visível" da universidade para o grande público [...];

Os museus universitários deverão constituir um meio [...] com que a universidade pode contar para levar sua ação de sensibilização dos jovens pré-universtiários para as atividades científicas, bem como de divulgação cultural (no sentido mais amplo) às populações que não a frequentam;

Tem o dever de proteger e valorizar o seu patrimônio histórico-artístico, facilitando a fruição dele pelo grande público e favorecendo o seu estudo pelos especialistas da própria universidade ou exteriores a ela;

Distinguem-se dos seus congêneres dependentes de outros organismos 
no fato das atividades enumeradas serem realizadas numa perspectiva universitária, dando origem a uma instituição híbrida que projeta a universidade nas populações que não a frequentam - influindo na sua qualidade de vida - bem como nos jovens que nela pretendem ingressar.

Analisando as propostas de Gil, podemos afirmar que os museus universitários agregam, às funções dos museus não universitários, as demandas por legitimação e difusão dos saberes, experiências, sensibilidades e representações do campo científico e da vida acadêmica, sendo também responsáveis por apresentar a Universidade aos não universitários.

Transportando essas características para o modelo brasileiro de universidade, cujas funções típicas são, por mandamento constitucional, o ensino, pesquisa e a extensão ${ }^{4}$, podemos compreender porque grande quantidade de museus universitários se vincula ou aos próprios departamentos onde surgiram as coleções que lhes deram origem - ou seja, se vinculam às unidades de pesquisa científica e de ensino - ou, mais contemporaneamente, estão vinculados às unidades administrativas da extensão ${ }^{5}$, pois, estas são as "responsáveis" pelo contato com a sociedade.

Mesmo quando os museus universitários não são formalmente vinculados às unidades extensionistas, muitas vezes os financiamentos universitários para os museus provêm da extensão, pois, as atividades vinculadas aos museus não costumam ser encaradas como atividades de pesquisa, conforme discutiremos a seguir.

Há, portanto, que se refletir sobre a configuração do campo científico, de um lado, e, do outro lado, sobre a relação (não harmoniosa, na prática) entre ensino, pesquisa e extensão e seu impacto na gestão dos museus universitários. Para tanto utilizamos como ferramentas de análise a teoria do funcionamento dos campos, tal como proposta por P. Burdieu, e sua aplicação no contexto da especialização das funções das universidades no Brasil.

\section{Museus universitários: o campo científico, a função ensino e a função pesquisa}

De acordo com Bourdieu (2004) o conceito de campo é operacional no sentido de analisar o funcionamento de determinados setores do mundo social que possuem características e regras de funcionamento autônomas, embora sejam também influenciados pelo contexto social geral. Nas palavras do autor:

A noção de campo está aí para designar esse espaço relativamente autônomo, esse microcosmo dotado de suas leis próprias. Se, como o macrocosmo, ele é submetido a leis sociais, essas não são as mesmas. Se jamais escapa às imposições do macrocosmo, ele dispõe, com relação a este, de uma autonomia parcial mais ou menos acentuada (BOURDIEU, 2004, p. 20-2I).

Uma vez que o campo científico dispõe de autonomia de funcionamento, também é importante lembrar que ele maneja capitais próprios, valores e poderes que lhes são particulares. Este tipo de capital, nomeado por Bourdieu como capital científico, pode ser conceituado como

4 Conforme exposto na Constituição Federal de 1988, art 207: “As universidades gozam de autonomia didático-científica, administrativa e de gestão financeira e patrimonial, e obedecerão ao princípio de indissociabilidade entre ensino, pesquisa e extensão" (BRASIL, 1988).

5 Breve levantamento, amostral, aponta museus ou memoriais vinculados às unidades administrativas da extensão na USP, UFPE, UFRPE, UFS, UFPR, UFSC, UFRGS, UFRJ, UFMA, UFS, UFMT, etc. Esta pesquisa ainda está por ser realizada de maneira sistemática, contudo, nossa intenção é apenas apontar para uma realidade que precisa ser analisada, porém, ainda carece de estudos acadêmicos. 
uma espécie particular do capital simbólico (o qual, sabe-se, é sempre fundado sobre atos de conhecimento e reconhecimento) que consiste no reconhecimento (ou no crédito) atribuído pelo conjunto de pares-concorrentes no interior do campo científico (BOURDIEU, 2004, p. 26).

Estes capitais funcionam como moedas que se recolhem de acordo com as funções e atividades realizadas pelos docentes nas universidades e se distribuem, de maneira desigual, entre atividades de ensino, de pesquisa e extensão.

O capital científico se expressa através de duas formas de atuação, principais, no campo científico: uma atuação temporal/política e outra atuação "científica pura", por assim dizer.

No caso da atuação temporal/política estamos nos referindo àqueles agentes que têm uma atuação institucional voltada para o funcionamento quase que burocrático - mas não menos importante - do campo científico, ou seja,

que está ligado à ocupação de posições importantes nas instituições científicas, direção de laboratórios ou departamentos, pertencimento a comissões etc., e ao poder sobre os meios de produção (contrato, créditos, postos etc.) e de reprodução (poder de nomear e de fazer as carreiras) que ela assegura (BOURDIEU, 2004, p. 35).

Neste contexto estão as chefias de departamento, as coordenações de cursos de graduação e pós-graduação, entre outras atividades ligadas ao ensino e à pesquisa, cujos ganhos simbólicos são bastante altos.

Porém, cumpre, desde já, observar que a direção e administração de museus não costuma ser um do posto de direção que gera grande capital científico na modalidade temporal/política. Amparamos esta afirmação na análise de Delicado (2008), cuja pesquisa analisa os museus de ciência de universidades portuguesas:

os museus tutelados por instituições do campo científico são necessariamente dirigidos por docentes ou investigadores. Estes cargos são ocupados por indivíduos com um interesse particular pela museologia ou divulgação científica ou por docentes do respectivo departamento, escolhidos em regime de rotatividade ou por responderem a necessidades específicas do museu. São geralmente profissionais que já atingiram o topo das suas carreiras, com tempo disponível para dedicarem a uma actividade que é pouco valorizada no campo científico (PAOLA, 2004), no qual os capitais são acumulados através da docência, dos projectos de investigação e da publicação de artigos em revistas (DELICADO, 2008, p. 57).

Para referendar a tese do pouco prestígio gerado pelos postos administrativos nos museus universitários brasileiros, podemos lançar mão das pesquisas realizadas por Marques e Silva (201 I, p. 78) no contexto dos museus da UFBA, e Silva Filho (2013) no contexto da gestão dos acervos de patrimônio cultural de ciência e tecnologia da UFPE.

Após entrevistar gestores de quatro museus da UFPE, Silva Filho conclui: "Em nenhum momento os entrevistados se queixaram de seus salários, apenas fizeram menção ao não reconhecimento institucional por seu trabalho e pelos acervos que guardam" (SILVA FILHO, 2013, p. 109).

Mesmo em universidades públicas com maior tradição na gestão de museus universitários, como a USP, que possui museus desde a sua fundação, pode-se perceber um desequilíbrio entre o prestígio dos cargos de direção de 
museus e dos demais ambientes hierárquicos da instituição, conforme apontou, em 200I, Mortara:

No Conselho Deliberativo de cada museu há participação de docentes representando as unidades afins; entretanto, como destaca Ulpiano Meneses, não há;representantes dos museus nos Conselhos das unidades afins. Além disso, cada museu deve indicar uma lista tríplice para submeter ao Reitor na escolha de seu diretor; este deve ser no mínimo titular e até o momento não há titulares procedentes dos museus. Assim, os diretores indicados vêm dos departamentos afins (MENESES apud MORTARA, 200I, p. 6I-62).

Apesar de não dispormos de dados produzidos em pesquisas exaustivas sobre a realidade dos museus das universidades públicas brasileiras, acreditamos que existem dados suficientes para afirmar que os cargos de diretoria de museus universitários são assumidos em detrimento de atividades que geram maior prestígio, maior rendimento, seja no âmbito do capital científico com uma atuação temporal/política, seja no âmbito do capital científico com atuação "científica pura".

Nesta outra modalidade de atuação, a do capital científico puro, os museus universitários fornecem ainda menos prestígio.

O capital científico puro está amparado principalmente nas "contribuições reconhecidas ao progresso da ciência, as invenções ou as descobertas (publicações, especialmente nos órgãos mais seletivos e mais prestigiosos...)" (BOURDIEU, 2004, p. 36). No contexto do sistema de avaliação do campo científico no Brasil, trata-se de ganhos relacionados principalmente com a atividade de pesquisa e com seus mecanismos de legitimação (publicações em periódicos com Qualis, participação em projetos de pesquisa financiados, geração de patentes etc.).

Assim, qualquer atividade que não produza lucros neste campo é desvalorizada institucionalmente. Contudo, mais do que a desvalorização institucional, cumpre-nos lembrar que a preponderância deste tipo de capital no campo científico tem um impacto também nas condições materiais de preservação dos acervos dos museus universitários, pois, os recursos econômicos destinados a produzir capital científico puro são muito maiores do que os recursos destinados à manutenção de museus universitários.

Embora esta situação seja, aparentemente, paradoxal, estamos, no fundo, tratando da especificidade dos museus e coleções universitárias, que analisamos anteriormente: as coleções universitárias foram criadas para o ensino e a pesquisa, a elas subordinadas, por assim dizer.

Em última instância, e com manifesto exagero didático, poderíamos afirmar que os museus e coleções universitárias foram criados para garantir a pesquisa, para garantir a produção do capital científico puro. Esta contextualização - e mesmo o exagero didático - são importantes para que possamos compreender o quanto a desvalorização dos acervos e museus universitários, no contexto da administração interna das universidades, está relacionada à sua pouca funcionalidade no âmbito da pesquisa científica.

Os museus universitários existem desde o século XVIII, contudo, apenas no século XIX estes começaram a generalizar sua preocupação com o atendimento especializado ao público não universitário (GIL, 2005, p. 43), entretanto, pode-se afirmar que os recursos destinados às atividades externas foram sempre limitados, em comparação com a função principal dos acervos, que era 0 atendimento às necessidades internas das universidades. 
O ponto de descenso na gestão dos museus universitários ocorreu quando o ensino e a pesquisa começaram a ter seus métodos e objetos modificados pela miniaturização e pela virtualização. $O$ século $X X$, em especial na sua segunda metade, assistiu a uma grande mudança nos métodos e objetos de estudo das universidades, que passaram do campo macro ao campo micro, ou seja, a investigação científica afastou-se

daquilo que podemos designar por 'objeto museológico', centrando-se cada vez mais no átomo e na molécula, tornando, na opinião de diversos especialistas, os Museus de História Natural organismos obsoletos no que respeita ao ensino e à investigação (GIL, 2005, p. 43).

Embora o próprio Gil relativize este afirmação para o contexto geral europeu, podemos observar, até por experiência empírica, que os métodos e materiais de ensino e pesquisa científica foram amplamente impactados pela lógica da renovação tecnológica.

Conforme explicam Favacho e Mill (2007), na sociedade contemporânea, o saber tende sempre a ser associado à inovação tecnológica:

a relação de saber que engendra poder é marcada por um conturbado processo de inovações tecnológicas em curto prazo. Em decorrência dessa aceleração das inovações em curto prazo, as relações de saber tornam-se efêmeras à medida que a crítica ao saber tecnológico é substituída pelas facilidades da técnica (inovação). Isto significa dizer que o vínculo estabelecido entre os aspectos privilegiados da cultura ocidental e o discurso tecnológico conduz tal discurso para uma verdade vaga, porém inquestionável, a saber: a metamorfose do discurso tecnológico. Em outras palavras, o discurso tecnológico tem a pretensão de desviar-se de qualquer conservadorismo e de viver basicamente de supostas vanguardas (FAVACHO; MILL, 2007, p. 209).

Longe de entender a renovação tecnológica como a vilã responsável pela crise dos museus universitários enquanto fonte de pesquisa, queremos chamar atenção para o fato de que os museus e coleções universitárias mudaram de função quando deixaram de ser a fonte privilegiada de dados/espécimes/exemplares/amostras para a pesquisa e passaram a receber valor cultural.

O movimento de atribuição de valor cultural está relacionado a um outro capital, outro poder simbólico, outra forma de distinção e de legitimação (PRADO, 20 I I, p. I 28), não tradicionalmente manejado pelas universidades para tratar de si próprias. Este movimento é recente se pensarmos na longa trajetória institucional das universidades no ocidente e, no caso brasileiro, podemos afirmar que esta atribuição de valor cultural aos seus acervos ainda está em processo de implantação, posto que o nosso sistema de ensino superior é extremamente recente (meados do século XIX).

Podemos identificar na literatura outros exemplos, fora do âmbito da história natural, que nos indicam que museus e coleções universitárias com valor cultural - não utilizados para a pesquisa e o ensino - são criações recentes no âmbito europeu. Por exemplo, Lourenço explica como se deram os processos de musealização de instrumentos científicos em algumas universidades europeias:

Os instrumentos eram utilizados até à exaustão, tornando-se depois obsoletos e postos de lado (tipicamente, iam para o lixo ou, na meIhor das hipóteses, para uma cave ou um sótão). Apenas no século 
$\mathrm{XX}$ foram estas 'proto-coleções' organizadas em museus, geralmente na sequência de centenários ou celebrações - foi assim com o Museu de Utrecht, com o Museu de História da Ciência de Oxford, com o Museu/Gabinete doVolta em Pavia e com o Museu de Ciência da Universidade de Lisboa (LOURENÇO, 2009, p. 5 I, grifo nosso).

No caso dos museus de arte, a motivação para a constituição das coleções está relacionadaà busca por outro tipo de legitimação, vinculada à distinção que o capital simbólico cultural pode gerar (PRADO, 20 I I), conforme exemplifica Mortara sobre o contexto britânico:

A posse de valiosas coleções dava prestígio às universidades, tanto pelo fato de poderem utilizá-las para ensino e pesquisa como pela criação de uma imagem de patrocinadoras/protetoras das artes e ciências. Nas décadas de 60 e 70 muitas universidades britânicas tornaram-se responsáveis por museus e coleções que estavam com problemas financeiros e também adquiriram outras importantes coleções. Com a crise financeira das universidades nos anos 80 , passou-se a questionar a sua capacidade de gerir todo esse patrimônio (MORTARA, 200 I, p. 26).

Certamente este quadro analítico que estamos traçando é bastante genérico, contudo, podemos afirmar com segurança que mesmo no contexto europeu, a institucionalização do patrimônio universitário ${ }^{6}$ é recente (século $\left.X X I\right)^{7}$, e que esta institucionalização pressupõe a atribuição de um valor cultural a um grande conjunto de bens que, durante séculos, só teve valor enquanto ferramenta para a geração de capital científico.

No caso brasileiro, estamos falando de universidades jovens, em sua esmagadora maioria criadas já no século $X X$, sem uma experiência acumulada com a gestão dos museus e coleções universitários, os quais têm sido criados a serviço da pesquisa (especialmente no caso das ciências da terra e de algumas áreas que necessitam do espécime como os herbários, ou as coleções zoológicas, entre outras) ou, o que é mais comum, são fruto de ações individuais de pesquisadores, ou grupos de pesquisadores, que têm particular sensibilidade para a preservação de algum acervo.

Esta atividade individual, personalista até, também ocorre nas universidades mais jovens da Espanha, conforme explica Fernandéz, afirmando que os novos museus têm em comum o fato de terem "sido gerados graças ao esforço e dedicação de uma pessoa que com seu entusiasmo conseguiu envolver profissionais e voluntários de diversas disciplinas, transformando em realidade um projeto duradouro" (GARCÍA FERNANDÉZ, 2012, p. I05).

Deste modo, retomamos o argumento de que os museus universitários, nos dias atuais, não costumam gerar capital científico e, por este motivo não recebem suficiente valorização no ambiente institucional universitário, estando sempre em

6 Ressaltamos a diferença entre patrimônio universitário e museu universitário, contudo, há que se observar que os movimentos de valorização, e desvalorização, de ambos são um processo único, pois, na origem, os acervos que os compõem serviam para a pesquisa científica, tendo sofrido o mesmo processo mudança de utilização quando passaram a necessitar da atribuição de valor cultural para garantir sua sobrevivência.

7 Ver, por exemplo, o Manifeste pourl'intégracion des museés et collections dans la politique scientifique et culturelle des universités, produzido por 70 profissionais de museus das mais importantes universidades francesas em 2012. Disponível no site do Comitê Internacional do Icom para os Museus e Coleções Universitárias. Disponível em: <http://publicus.culture.hu-berlin.de/umac/pdf/MANIFESTE-Muse\%CC\%8I es\%20 et\%20collections\%20universitaires.pdf>.Acesso em: 22 jul. 2013. 
situação de inferioridade na disputa por recursos humanos e materiais.

Esta situação se reflete até mesmo na disputa por condições mínimas de infra-estrutura material, tal como a alocação de espaço físico, a distribuição de verbas de manutenção, a reposição de funcionários, os recursos para publicação etc. As autoras Marques e Silva fazem uma lista de dificuldades encontradas na gestão dos museus da UFBA, a saber:

I) dificuldades financeiras; 2 ) falta de autonomia; 3) tensões nas relações com departamentos (entre professores, estudantes e funcionários) e com as comunidades universitária e local; 4) pressão dos departamentos para a utilização do espaço; 5) abandono das coleções; 6) falta de espaço para armazenamento e para a exposição; 7) falta de profissionais especializados em atividades museológicas; 8 ) chefia exercida por pessoas sem formação na área museológica; 9) acúmulo de função por parte dos dirigentes (MARQUES; SILVA, 20I I, p. 78).

Enquanto Silva Filho identificou demandas muito semelhantes entre os gestores de museus da UFPE: "Verbas para manutenção, reconhecimento institucional e déficit de pessoal foram as dificuldades mais referidas pelos gestores" (SILVA FILHO, 20I3, p. I I0). Segundo os mesmos gestores entrevistados por Silva Filho, os museus não lhes propiciam ganhos no campo científico, seus ganhos são de outra natureza, "expressos através de depoimento emocionado como: '[...] cuido dele porque ele é meu filho'” (SILVA FILHO, 20 I3, p. I I0).

Certamente poderíamos estender essa realidade para a enorme maioria dos museus universitários brasileiros, pois, de maneira ampla, podemos afirmar que nas universidades brasileiras a função pesquisa está dissociada dos museus, e vice versa.

$\mathrm{Na}$ disputa por melhores condições de trabalho os detentores do capital científico precisam, para sua própria manutenção, optar por, por exemplo, direcionar os funcionários existentes para a realização das atividades que garantam a execução financeira do Departamento, e não para o museu; na distribuição das escassas verbas do Departamento, os recursos destinam-se a adquirir um data-show para as atividades de ensino da graduação, não para o museu; na disputa por espaço físico para instalar um novo laboratório de análises científicas, perde a reserva técnica do museu. Enfim, os exemplos poderiam ser replicados ad infinitum, pois, nas atividades cotidianas das universidades, os capitais científicos relegam a gestão dos museus a segundo plano, a fim de garantir sua própria sobrevivência no campo científico.

Enfatizamos a importância de correlacionar a gestão dos museus com o funcionamento do campo científico, pois, são as dinâmicas internas deste campo - aliadas à gestão da coisa pública no Brasil - que atribuem o lugar dos museus nas universidades.

\section{Museus universitários e a extensão: limites e possibilidades}

A extensão é a faceta mais recente das universidades. Enquanto o ensino e a pesquisa estão na base do seu surgimento, ainda na Idade Média, a extensão é uma criação da universidade moderna, surgida apenas em 1808, na Alemanha, e nas universidades populares, também surgidas no século XIX, com a função de disseminar os saberes técnicos (CARVALHO, 20I I, p. 19).

No Brasil a função extensionista se consolidou com a Lei Básica da Reforma Universitária (Lei n. 5.540/68), que normatizou a atuação extensionista 
das universidades ${ }^{8}$. Desde então, podemos afirmar que a função extensão vem crescendo a passos largos, especialmente no Brasil e na América Latina (FORPROEX, 20I2), tendo se consolidado atualmente com o seguinte conceito:

A Extensão Universitária, sob o princípio constitucional da indissociabilidade entre ensino, pesquisa e extensão, é um processo interdisciplinar, educativo, cultural, científico e político que promove a interação transformadora entre Universidade e outros setores da sociedade (FORPROEX, 2012, p. 15).

Contudo, apesar do muito que se escreve sobre a necessária integração entre ensino, pesquisa e extensão, sabemos que, do ponto de vista da infraestrutura e dos recursos materiais e humanos, a extensão é a mais frágil das funções das universidades brasileiras, conforme aponta Carvalho (20 I I, p. I2):

É notória a pequena importância que se dá à extensão universitária enquanto produção acadêmica e disponibilidade de recursos pelos órgãos de fomento. $A$ ausência de um órgão regulador e fomentador da extensão em âmbito nacional, como acontece com o Conselho $\mathrm{Na}$ cional de Desenvolvimento Científico e Tecnológico (CNPq) na área de pesquisa e com a Coordenação de Aperfeiçoamento de Pessoal de Nível Superior (CAPES) na pós-graduação, pode ser fator de desvalorização da extensão no seio das universidades, que muitas vezes não consideram essas ações como atividades acadêmicas. $O$ currículo lattes, por exemplo, não leva em conta participações nas ações extensionistas ${ }^{9}$, sendo, ele, considerado no ambiente acadêmico como o grande e, por muitos, o exclusivo instrumento de avaliação do grau de excelência dos docentes.

Do ponto de vista orçamentário, é importante lembrar que a extensão ainda não está sequer institucionalizada nas diretrizes orçamentárias do governo federal (planos plurianuais, a partir do qual são geradas as leis orçamentárias federais) (FORPROEX, 20I2, p. 29), ou seja, os recursos financeiros são escassos e instáveis.

Poderíamos mencionar uma série de outros elementos que apontam a fragilidade da extensão no âmbito das universidades brasileiras, contudo, para os fins deste trabalho, importa tão somente considerar que se trata de uma atividade recente, cujos mecanismos de institucionalização e legitimação ainda se encontram em construção, da mesma maneira que o lugar dos museus e acervos universitários nesta função.

Assim, podemos apontar, novamente, para os poucos ganhos de capital, tanto simbólico quanto econômico, neste novo lugar institucional dos museus e coleções universitárias. Mais uma vez, gestores de museus ganham pouco reconhecimento e prestígio institucional, pois, estão vinculados à função mais frágil da universidade.

$\mathrm{Na}$ falta de espaços institucionais vinculados às atividades de ensino e pesquisa, os museus e acervos universitários assumem a função de equipamentos de difusão dos conhecimentos da universidade para os não universitários. Por um lado, podemos dizer que este espaço institucional, apartado dos espaços

8 Existem referências a ações extensionistas desde o início das experiências universitárias brasileiras, porém, destaca-se o período entre 1968 e 1996, ano da promulgação da Lei de Diretrizes e Bases da Educação Nacional (Lei 9394, 20/I2/1996), como um período importante para o desenvolvimento das atuais feições da extensão. Deve-se ressaltar especialmente a criação do Fórum de Pró-Reitores de Extensão das Universidades Públicas Brasileiras-FORPROEX em 1987 e a Constituição de 1988. (FORPROEX, 20I2).

9 Só recentemente foi inserida uma seção específica para os projetos de extensão no Curriculum Lattes; o texto citado é de $201 \mathrm{I}$. 
onde são desenvolvidos os ganhos de capital científico, reforça uma certa exclusão do museu universitário que se aparta, ainda mais, dos principais espaços de poder e mecanismos de legitimação do campo científico.

Porém, por outro lado, a reversão deste quadro pode estar em construção. No âmbito da extensão vêm sendo construídos - com rapidez, se compararmos com a trajetória do ensino e da pesquisa - conceitos e práticas que abrem um maior espaço para uma atuação mais efetiva dos museus universitários e, consequentemente, uma maior força institucional na disputa por recursos para a sua gestão.

Para compreendermos melhor esta possibilidade que parece estar em construção, é importante lembrar que o conceito de extensão no Brasil passou por diferentes fases, antes de adquirir as feições atuais:

Da extensão cursos, à extensão serviço, à extensão assistencial, à extensão 'redentora da função social da Universidade', à extensão como mão dupla entre universidade e sociedade, à extensão cidadã, podemos identificar uma resignificação da extensão nas relações internas com os outros fazeres acadêmicos, e na sua relação com a comunidade em que esta inserida (SERRANO, [20I I?], p. I).

A atual concepção de extensão universitária tem origens epistemológicas que são muito próximas às concepções de museu que foram propostas durante as reuniões de Santiago do Chile (1972) e Caracas (1992).

As trajetórias, e os autores que embasam estas trajetórias, são muito semelhantes. O mesmo Paulo Freire que debateu o papel autoritário da extensão, criticando a "extensão como um momento autoritário da universidade, que desconhecendo a cultura e o saber popular, apresentava-se como detentora de um saber absoluto, superior e redentor da ignorância" (SERRANO, [20 I I?], p. 2), foi também o inspirador da Declaração de Santiago ${ }^{10}$, quando esta tratou da nova forma de atuar dos museus latino-americanos:

A tomada de consciência, pelos museus, da situação atual e das diferentes soluções que se podem vislumbra para melhorá-la, é condição essencial para sua integração à vida da sociedade. Dessa maneira, consideraram que os museus podem e devem desempenhar papel decisivo na educação da comunidade (DECLARAÇÃO DE SANTIAGO, 1972 apud BRUNO, 2010, p. I).

Vinte anos depois, ambos conceitos passaram por atualizações e adaptações, passando a propugnar não mais a necessidade da intervenção dos museus, e da extensão universitária, em uma dada comunidade que precisaria ser conscientizada, mas, sim, reconhecendo a "Comunidade como cogestora desses bens, com sua visão própria e seus próprios interesses” (HORTA, 2010, p. 65).

Para os museus, a declaração de Caracas propugnou, principalmente, a integração dos museus à vida comunitária. Neste mesmo período foi formulado o atual conceito de extensão, baseado na perspectiva de Santos, que incorporou o conceito de "interação dialógica entre a Universidade e a sociedade" (FORPROEX, 20I2, p. I0).

É possível perceber que existe uma matriz conceitual muito próxima, como já se apercebera Santos:

Considero que a área de extensão, nesse novo contexto, terá uma importância vital na construção da pluriuniversidade e será responsável

IO E só não foi debatedor principal daquela conferência porque seu nome foi vetado pelo delegado brasileiro junto à UNESCO, por questões políticas (VARINE, 20I0, p. 39). 
por promover transformações importantes na organização dos currículos dos cursos das diversas áreas, na formação e na carreira docente. Comentando a importância da extensão pra a universidade do sec. XXI, Santos (2005, p. I75) registra que a reforma da universidade deve conferir uma nova centralidade às atividades de extensão e concebê-las de modo alternativo ao capitalismo global, atribuindo às universidades uma participação ativa na construção da coesão social, no aprofundamento da democracia, na luta contra a exclusão social e a degradação ambiental e na defesa da diversidade cultural (SANTOS, 2008, p. 235).

Esta proximidade de conceitos pode transformar os museus e coleções universitárias em um veículo privilegiado de comunicação entre a universidade e a sociedade, ao invés de apenas apresentar a universidade aos não universitários.

Se a extensão ainda não produz grande quantidade de ganhos de capital simbólico, poderão os museus universitários colaborar na sua institucionalização e legitimação. Poderão, museu e extensão crescer juntos, propiciando mútuo apoio e melhores condições de desenvolvimento institucional.

Novos estudos e planos de ação precisam ser construídos para que os museus universitários e a extensão universitária se integrem, proporcionando a exploração dos valores culturais para os acervos sob guarda das universidades. Trata-se de um campo ainda em construção no ambiente acadêmico, porém, o reforço da institucionalização dos museus como espaços privilegiados de uma extensão dialógica, poderá criar os mecanismos de institucionalização dos museus, propiciando ganhos simbólicos e materiais para os agentes envolvidos na gestão dos museus e oportunizando uma revalorização destes no contexto da gestão universitária como um todo.

\section{Referências}

BAZZO, Walter Antonio. Ciência, tecnologia e sociedade e o contexto da educação tecnológica. 3. ed., rev. Florianópolis: Ed. da UFSC, $201 \mathrm{l}$.

BOURDIEU, Pierre. Os usos sociais da ciência: por uma sociologia clínica do campo científico. São Paulo: UNESP, 2004.

BRASIL. Constituição (1988). Diário Oficial [da] República Federativa do Brasil, Poder Executivo, Brasília, DF, 05 out. 1988. Seção I, p. I. Disponível em: <http://www. planalto.gov.br/ccivil_03/Constituicao/Constituicao.htm>.Acesso em: 22 jul. 2013.

BRASIL. Lei $n^{\circ}$ II.904, de 14 de janeiro de 2009. Estatuto dos museus. Diário Oficial [da] República Federativa do Brasil, Poder Executivo, Brasília, DF, I5 jan. 2009. Seção I, p. I. Disponível em: <http://www.planalto.gov.br/ccivil_03/_ Ato2007-20 10/2009/Lei/LI 1 904.htm>.Acesso em: 22 jul. 2013.

BRUNO, Maria Cristina de Oliveira. O ICOM/Brasil e o pensamento museológico brasileiro: documentos selecionados. São Paulo: Pinacoteca do Estado, 2010.

CARVALHO, Luciano de. Relações de parceria entre universidade e extensão universitária na UFJF. 20I I. Rio de Janeiro. Dissertação (Mestrado em Educação)- Universidade Estácio de Sá, Rio de Janeiro, 201 I.

DELICADO, Ana. Os museus e a promoção da cultura científica em Portugal. Sociologia, Problemas e Práticas [online], n. 5I, p. 53-72, 2006. Disponível em: <http://www.scielo.oces.mctes.pt/scielo.php?.pid=S0873$-65292006000200004 \&$ script=sci_arttext>.Acesso em: 06 dez. 2012

FAVACHO,André; MILL, Daniel. Funções do discurso tecnológico na sociedade contemporânea. Pro-Posições, v. I8, n. 2 (53), maio/ago. 2007. Disponível em: 
<http://mail.fae.unicamp.br/ proposicoes/textos/53-artigos-favachoa_etal.pdf>. Acesso em: 22 jul. 2013.

FORPROEX. Política nacional de extensão universitária. Manaus, 2012. Disponível em: <http://www.renex.org.br/documentos/2012-07- I3-Politica-Nacional-de-Extensao.pdf>.Acesso em: 22 jul. 2013.

GARCÍA FERNANDÉZ, Isabel. Reflexión y renovación de los museos universitarios: dos ejemplos de la Universidad Complutense de Madrid. In:ASENSIO, M. et al. (Ed.). Colecciones científicas y patrimonio natural. [S.I.: s.n.], 20I2. (Series de investigación iberoamericana de museología, v. 3, n. 5). Disponível em: $<$ https:// sites.google.com/site/mikelasensiobrouard/iii-siam>.Acesso em: 22 jul. 2013.

GIL, F. B. Museus universitários: sua especialidade no âmbito da museologia. In: SEMEDO, A.; SILVA, A. C. F. da.Coleções de ciências físicas e tecnológicas em museus universitários:homenagem a Fernando Bragança Gil. Porto: Faculdade de Letras da Universidade do Porto, 2005.

HORTA, Maria de Lourdes Parreiras.Vinte anos depois de Santiago: a declaração de Caracas. In: BRUNO, Maria Cristina de Oliveira. O ICOM/Brasil e o pensamento museológico brasileiro: documentos selecionados. São Paulo: Pinacoteca do Estado, 2010.

LOURENÇO, Marta Catarino. O patrimônio da ciência: importância para a pesquisa: museologia e patrimônio. Revista Eletrônica do Programa de Pós-Graduação em Museologia e Patrimônio, v. 2, n. I, jan./jun. 2009. Disponível em: <http:// revistamuseologiaepatrimonio.mast.br/index.php/ppgpmus/article/view/45/25>. Acesso em: 06 dez. 2012.

MARQUES, Roberta Smania; SILVA, Rejâne Maria Lira da. O reflexo das políticas universitárias na imagem dos museus universitários: ocaso dos museus da UFBA. Museologia e Patrimônio - Revista Eletrônica do Programa de Pós-Graduação em Museologia e Patrimônio, v. 4, n. I, 20II. Disponível em: <http://revistamuseologiaepatrimonio.mast.br/index.php/ppgpmus/article/view/|49/I5I>. Acesso em: 22 jul. 2013.

POULOT, D. Nação, museu, acervo. In: BITTENCOURT, J. N.; BENCHETRIT, S. F.; TOSTES, V. L. B. História representada: o dilema dos museus. Rio de Janeiro: Museu Histórico Nacional, 2003.

PRADO, M. M. N.P.A teoria de campo e o patrimônio cultural. Museologia e Patrimônio - Revista Eletrônica do Programa de Pós-Graduação em Museologia e Patrimônio, v. 4, n. I, 20 I I. Disponível em: <http://revistamuseologiaepatrimonio. mast.br/index.php/ppgpmus/article/viewFile/I54/I54>. Acesso em: 06 dez. 2012.

SANTOS, Maria Célia Teixeira Moura. Encontros museológicos: reflexões sobre a museologia, a educação e o museu. Rio de Janeiro: MINC/IPHA/DEMU, 2008.

SERRANO, Rossana Maria Souto Maior. Conceitos de extensão universitária: um diálogo com Paulo Freire. [20I I ?]. Disponível em: <http://www.prac.ufpb.br/ copac/extelar/atividades/discussao/artigos/conceitos_de_extensao_universitaria.pdf>. Acesso em 22 jul. 2013.

SILVA FILHO,Arlindo Francisco. Patrimônio, memória, ciência e tecnologia: gestão do patrimônio cultural de ciência e tecnologia do Centro de Tecnologia e Geociências da Universidade Federal de Pernambuco. 2013. Dissertação (Mestrado em Gestão Pública)- Universidade Federal de Pernambunco, Recife, 20I3. UNIÃO EUROPÉIA. Recommendation of the committee of ministers to member states on the governance and management of university heritage. 2005. Dis- 
ponível em: <http://publicus.culture.hu-berlin.de/umac/pdf/Rec_2005_|3E.pdf>. Acesso em: 22 jul. 2013.

VARINE, Hugues. A respeito da mesa-redonda de Santiago. In: BRUNO, Maria Cristina de Oliveira. O ICOM/Brasil e o pensamento museológico brasileiro: documentos selecionados. São Paulo: Pinacoteca do Estado, 2010.

VERGER, Jacques. Universidade. In: LE GOFF, J.; SCHMITT,J. (Coord.). Dicionário temático do ocidente medieval. Bauru, SP: EDUSC, 2002. v. 2.

Artigo recebido em junho de 2013. Aprovado em agosto de 2013 